\title{
GOLPE DO VERSO
}

LE COUP DU VERS

João Alves Rocha Neto*

RESUMO: O presente ensaio pretende, a partir do verso emblemático de Mallarmé - un coup de dés jamais n'abolira le hasard -, refletir sobre função de resistencia que a palavra poratica assume ror diferenca em um mundo cada vez mais preocupado na pormactio a melç ceste dore dor, co: Benjamin e Maurice Blanchot.

PALAVRAS-CHAVE: golpe do verso; transposição; palavra poética
* jarochabr@yahoo.com.br

Professor de Língua Portuguesa e Literatura na Rede Municipal de Ensino de Belo Horizonte e Doutor em Teoria da Literatura e Literatura Comparada pela UFMG.

RÉSUMÉ: Cet essai pretend, à partir du vers emblematique de Mal作 de résistence que le mot poétique assume par afirmer la difference dans un monde qui s'occupe de plus en plus de l'afirmation du semblable ce que nos amène plusiers fois à l'aniquilation de l'autre. Ce travail donc se promène par l'oeuvre de quelques poètes, écrivains et penseurs, comme: Mallarmé, Herberto Helder, Maria Gabriela Llansol, penseurs, comme: Mallarmé, Herberto Helder, Maria Gabriela Llansol, Silina Rodrigues Lopes, Jacques Lacan, Roland Barthes, Derrida, Walet Maurice Blanchot.

MOTS-CLÉS: coup du vers; transposition; mot poétique 
1. MALLARMÉ. Un coup de dés jamais n'abolira le hasard, $\mathrm{s} / \mathrm{p}$

2. LLANSOL. Hölder de Hölderlin, s/p.

3. Cf. Crise do verso. In: MALLARMÉ. Divagações.

4. MALLARMÉ. Divagações, p. 158
"Não é a cultura que precisa da poesia para se enriquecer, é a poesia que precisa de uma cultura que a permita, isto é, que aceite que há em cada homem a potencialidade de se relacionar com os outros pela afirmação da dissemelhança, a sua maneira única de participar do

mundo".

Silvina Rodrigues Lopes, em Literatura, defesa do atrito.

"Un coup de dés jamais n'abolira le hasard"1. Esse verso de Mallarmé, que aqui traduzo como "um golpe de dados jamais abolirá o acaso", acompanha, de muito perto, o que "é tão ligeiro que cairá sem se ver", ${ }^{2}$ isto é, a palavra poética Talvez porque, em suas letras, escreva-se o que passa tão rápido que só podemos perceber pelos vestígios que deixa: o golpe. E o que isso nos aponta? Em um primeiro momento, se pensarmos com o poeta, o golpe aponta para uma crise: a crise do verso ${ }^{3}$ - título de um primoroso texto de Mallarmé. Nele, sublinha-se a crise do verso parnasiano, com sua métrica perfeita, que naquela época ainda povoava os círculos literários, pois a palavra poética começava a ser invadida pela "multiplicidade dos gritos de uma orquestração"4 que a levava a uma certa desmedida, a uma implosão da métrica alexandrina, para que outros elementos pudessem ter lugar na leitura: o branco da página, o espaço de uma letra à outra, o silêncio. $\mathrm{O}$ verso, algo antes enrijecido pela métrica, agora se encontra livre, ou melhor, polimorfo, como o define Mallarmé. A metamorfose passa a ser o seu devir e com isso ele pode ser a forma condensada da literatura, pois é como se cada verso contivesse o mundo todo ou como se ele fosse a própria metonímia do mundo: "um mundo por vir contido numa semente semântica de mostarda” ${ }^{5}$ Dessa maneira, neste trabalho, não farei diferença de gênero quando me refiro ao poema, à narrativa e ao romance. O que não quer dizer que desconsidere suas diferenças, mas que o que me interessa aqui, como veremos adiante, é a potência desestabilizadora que a palavra poética carrega em todas essas formas.

Voltemos ao verso de Mallarmé. Embora o poeta afirme que o golpe que impulsiona essa crise do verso não ocasiona um apagamento da tradição, isto é, de nada que tenha "sido belo no passado", ${ }^{6}$ ele sublinha que esse verso polimorfo marca a decadência das escolas literárias que, presas em suas próprias regras, abolem as matérias naturais ou o que as excede, o que não tem forma - o intenso, por exemplo -, pois, de tão estáticas, seu verso não suportava o desconhecido que o invadia e que marcava a passagem para o século XX: "o horror da floresta", "a trovoada muda esparsa na folhagem" e "a madeira intrínseca e densa das árvores".?

Nesse sentido, há uma "desaparição elocutória do poeta" e, com esse desaparecimento, sua voz se torna a voz das palavras, ${ }^{9}$ pois são elas que inscrevem a passagem do mundo para a página do papel. São elas "o mais fino instrumento de representação do mundo” ${ }^{10} \mathrm{O}$ poeta, mesmo desaparecido, é o responsável por essa transposição. ${ }^{11} \mathrm{E}$ aqui chegamos a uma
5. LLANSOL. Onde vais, DramaPoesia?, p. 98.

6. MALLARMÉ. Divagações, p. 161

7. MALLARMÉ. Divagações, p. 163 164

8. MALLARMÉ. Divagações, p. 164

9. MALLARMÉ Divagações, p. 164

10. RAWET. Eu-tu-ele. p.99-100

11. Cf. PAULA. Cor'p'oema Llansol.
EM TESE
BELO HORIZONTE
v. 23
N. 1
JAN.ABR. 2017
ROCHA. Golpe do verso
P. $30-37$ 
12. LOPES. A Inocência do devir, p.

13. LOPES. Anomalia poética, p. 252.

14. LOPES. Anomalia poética, p. 133.

15. HELDER. Servidões, p. 12 importante consideração: a transposição é o golpe. Ela chega para desestruturar o verso bem comportado e fazer com que ele assuma outra forma: o mundo compactado. Assim, ele já não busca o sentido, pois está prenhe de sentido, de sentidos, de potenciais nascimentos que fazem com que o poema seja uma anomalia: "o sítio de acabar com o mundo e o sítio onde o mundo nasce". ${ }^{12} \mathrm{O}$ verso, que podemos pensar que é o próprio poema condensado, é pura concentração narrativa, pois “[...] um poema não é consumível, nem é objeto de uma recepção, o que é idêntico. Um poema não é um objeto como os outros: não é um objeto, nunca é como os outros. É essa a sua, a nossa, anomalia poética” ${ }^{13} \mathrm{O}$ poema é sempre incomparável.

Assim Silvina Rodrigues Lopes o define, dado que, como anomalia, ele é o lugar das singularidades. Não uma reunião de múltiplos significados, mas "um lugar de disseminação dos significados”, ${ }^{14}$ uma abertura e, portanto, encontra-se como uma forma sempre inacabada, a todo momento por se fazer e, por essa natureza metamórfica, sustenta sempre uma certa estranheza que é o cerne de sua força: causar atrito na cultura, deslocando, ininterruptamente, todo e qualquer discurso que aprisiona as diversas formas de saber. Em outras palavras, o poema é o que faz com que a verdade seja sempre esquiva. Ele é movimento de aproximação "porque o prestígio da poesia é menos ela não acabar nunca do que começar. É um início perene, nunca uma chegada seja ao que for". ${ }^{15}$
Este fora o golpe de dados lançado por Mallarmé: a transposição, e não mais a métrica, como estrutura do texto poético. Isso nos deu acesso ao aberto, ao excesso, ao que está sempre mais além. Abriu-nos para o futuro, o devir, um novo século. Abriu caminhos de tal maneira que, anos mais tarde, Jean-Luc Nancy pôde formular que "se compreendemos, se acedemos de um modo ou de outro a uma orla de sentido, é poeticamente" ${ }^{16} \mathrm{O}$ golpe do verso aberto por Mallarmé é transformar o poema em uma abertura, em um acesso de sentido e afirmar a palavra poética como um nascimento, como a intrusão de um novo sentido no mundo:

a fresta da carne,

a morte pela boca.

- Uma frase, uma ferida, uma vida selada ${ }^{17}$

E tal intrusão se dá num só golpe. O poema passa rápido, é certo. $\mathrm{O}$ infinito também é ligeiro. Por isso se escrevem somente no intempestivo e no inesperado de um golpe, pois ele também é o que não se espera e só o percebemos por seu acontecimento. Golpe de vento, golpe de ar, golpe do olhar, golpe de sorte, lapso da memória... O golpe do verso pode se aproximar de tantos outros, mas, se pudesse dizer sua principal característica, diria: a exatidão. Como aquilo que chega sem ser esperado, como uma graça, um dom, como um raio caído do céu em um ponto exato de um descampado, ele se
16. NANCY. Resistência da poesia, p.

\section{HELDER. Le poème continu:} somme anthologique, p. 288 
18. LLANSOL. Lisboaleipzig 1: o encontro inesperado do diverso, $\mathrm{p}$.
116.

19. DERRIDA. Che cos'è la poesia? inscreve como fogo, na exatidão das letras - portos do mistério e da noite -, a continuidade. O golpe do verso se dá para que o poema não morra, para que continue, como um dia escreveu Maria Gabriela Llansol sobre o romance:

_ escrevo, para que o romance não morra. Escrevo, para que continue,

mesmo se, para tal, tenha de mudar de forma,

mesmo que se chegue a duvidar se ainda é ele,

mesmo que o faça atravessar territórios desconhecidos,

mesmo que o leve a contemplar paisagens que lhe são tão difíceis de nomear ${ }^{18}$

A palavra poética é vulnerável, pois está sujeita ao golpe, como o poema-ouriço de Derrida ${ }^{19}$ - mônada que encerra no corpo o dentro e o fora, a cultura e a natureza - perdido em uma estrada, sujeito a todo e qualquer acidente. Ela é o acidente, o inesperado, o que atravessa nossa vida sem pedir licença e é tão rápida que pode nos deixar a pé, sem rumo e meio atônitos. $\mathrm{O}$ golpe também.

Face ao inesperado, restam-nos somente questões. Por exemplo: "que golpe pode o verso nos dar hoje? Que caminho pode nos abrir?". É importante sublinhar que o golpe do verso é também político, mas não é um golpe de Estado, pois não visa à aniquilação, ao retrocesso e à reafirmação do mesmo. Pelo contrário, seu movimento é em direção a um texto que tenta "abrir no real da política atos mais frequentes de dom poético, de compaciência pelos corpos que sofrem, e de alegria pelos que amam". ${ }^{20} \mathrm{Um}$ golpe de Estado encerra fecha, restringe os direitos, criando uma situação de exceção em que há a suspensão da lei, dando lugar à barbárie. E, nessa direção, toda e qualquer singularidade torna-se um crime. $\mathrm{O}$ poema, portanto, essa potência singular de multiplicidade e do novo, nesse contexto é criminoso.

O golpe do verso caminha em outra direção: propõe a ruptura necessária para que a palavra poética mantenha firme sua tarefa e responsabilidade - transpor o mundo para as páginas de um livro (seja ele em que formato for). Nessa transposição, sempre sobra alguma coisa, pois ela nunca é completa. Há sempre um resto e é esse resto, esse a mais, ${ }^{21}$ que promove a continuidade e a contaminação das vozes, propiciando, assim, uma experiência de comunidade em que o singular, e não o semelhante, é o ponto fulcral do afeto.

Derrida, em uma entrevista publicada com o nome Essa estranha instituição chamada literatura, diz que esse estranho encontra-se no fato de a literatura ser um lugar onde se pode dizer tudo, o que não quer dizer que se consiga tudo dizer, pois, como vimos, sempre há o resto. Mas o que ele marca é a liberdade que esse discurso nos apresenta e é nessa liberdade que ela se revela ainda mais estranha, pois a literatura é uma
20. LLANSOL. Carta de Llansol a Eduardo Prado Coelho.
21. Cf. CORREIA. a mais: uma experiência de leitura dos restos em Nuno Ramos. 
22. Cf. AGAMBEN. Por uma teoria do poder destituinte.

23. Maria Gabriela Llansol em carta a João Rocha (4 maio 2007). instituição que toma o partido do aberto e, portanto, traz consigo uma potência destituinte - ela institui destituindo.22 Pois seu movimento, como marca Derrida, é de se tornar em um só golpe, acessível e inacessível; ou nas palavras da escritora Maria Gabriela Llansol: "descobrir e encobrir constantemente o real". 23

Se o golpe também é marcado por uma ruptura institucional, o golpe do verso é válido, pois, havendo a ruptura, destituição de si mesma, a literatura abre-se ao novo, ao aberto, ao nascimento. Como a paisagem do cerrado que, para sobreviver, precisa da aniquilação pelo fogo, selando, assim, sua existência à destruição, o golpe do verso mostra-nos que a palavra poética, antes de tudo, é uma força da natureza e da cultura, pois está sempre no limiar, no litoral desses dois campos, por isso seu movimento natural de instituição destituinte: ela inscreve, na trama do simbólico, a desmedida do real. Nessa inscrição, esse golpe leva-nos para o que Barthes denominou como nuance e que tem no seu caminho a vida - sensação de existência de um sujeito -, mas para isso é necessário

um certo vazio realizado no sujeito; mesmo quando o júbilo (de amor), por exemplo, é mais intenso, é porque há no sujeito um vazio de linguagem; quando a linguagem se cala, quando não há mais comentário, interpretação, sentido, é então que a existência é pura: coração cheio (que "transborda") = conhecimento de um certo vazio (tema eminentemente místico); a falta, o desfalecimento do discurso remete a dois estados extremos: a miséria absoluta do "perdido", o júbilo ardente do "vivo" $\rightarrow$ A Nuance - se não a detemos - é a Vida - e os destruidores de nuances (nossa cultura atual, nosso jornalismo grosseiro) $=$ homens mortos que, no seio de sua morte, se vingam..$^{24}$

A nuance é, pois, esse ponto de acesso ao vazio, essa vida que, selada a cada verso inscrito na superfície do planeta, emerge para fazer atrito no discurso da "nossa cultural atual, de nosso jornalismo grosseiro", que insiste em ler o mundo dialogicamente, polarizando-o e fixando-o em dois lados, como se a vida só nos apresentasse dois caminhos possíveis. O golpe do verso é a terceira via, pois apresenta ao texto um acesso a outro tipo de ironia, não aquela do deboche ou da diminuição do outro, nem, muito menos, a que tem como meta produzir barulho a fim de que não ouçamos os passos firmes do tirano que se aproxima (bem aos moldes de nosso "jornalismo grosseiro"). A terceira via "é o outro lado da ironia, lado a que chamo fabuloso de uma ironia a que também chamo fabulosa, não por serem posse minha, mas por pertencerem a este fabulosamente vazio enigma do mundo". ${ }^{25}$

Nesse vazio enigma do mundo, a palavra ainda é mais frágil, pois, segundo Lacan, ela é acertada pela Coisa. O psicanalista marca que "em francês, a palavra $m o^{26}$ tem um peso e um
24. BARTHES. A preparação do romance, vol. 1, p. 98-99.

25. HELDER. Photomaton \& Vox, p. 12

26. "Mot" em francês significa "palavra".
EM TESE

BELO HORIZONTE

v. 23

N. 1

JAN.ABR. 2017

ROCHA. Golpe do verso

ค. $30-37$ 
27. LACAN. O seminário, livro 7: a ética da psicanálise, p. 71.

28. BLANCHOT. A parte do fogo, $\mathrm{p}$ 323.

29. Lembro-me fortemente dos de Gioconda Belli: "[Quero] um greve de olhos, de mão e de beijo. Uma greve onde respirar não seja permitido, / Uma greve onde nasça o silêncio / Para ouvir os passos do tirano que se vai". sentido particular. Mot é essencialmente 'nenhuma resposta'. Mot, diz La Fontaine, a certa altura, é o que se cala, é justamente aquilo para o qual nenhuma palavra é pronunciada". ${ }^{27}$ A palavra guarda consigo um certo silêncio: o silêncio das coisas. Segundo a tradição platônica, ela guarda a morte da coisa, mas Blanchot, movido pela abertura do golpe do verso de Mallarmé, avança, escrevendo que o silêncio inscrito nas palavras não é simplesmente a morte das coisas, mas "a vida que carrega a morte e nela se mantém". ${ }^{28} \mathrm{O}$ silêncio guardado pela palavra poética está mais ligado ao movimento que à paralisia. O silêncio abrigado pela palavra é, aqui, uma concentração narrativa e o que ele guarda é o devir das coisas. O golpe do verso, que marco neste verso de Mallarmé - "um golpe de dados jamais abolirá o acaso" - tira a palavra do lugar estático em que Platão a colocou, pois não é a morte das coisas que abriga, mas o nascimento ininterrupto do mundo. ${ }^{29}$

Nesse sentido, se há uma ética da literatura, se há uma relação entre literatura e democracia - esse eterno movimento de trazer para o centro da pólis o que lhe é absurdamente estranho, sustentando assim a (im)possibilidade de uma comunidade - ela só pode estar marcada pela responsabilidade de manter e sustentar o silêncio das palavras, pois é esse silêncio que faz atrito ao barulho ensurdecedor do discurso do poder que tenta a todo custo impor um texto em que as palavras não calam nada e, por meio de uma orquestração histriônica, provar que não é ele, mas sim, elas, as palavras, as responsáveis pela morte da coisa.

Assim, é preciso hoje, mais do que nunca, abrir caminhos em meio a um discurso que faz tanto barulho por nada e que pode nos levar, a todos, a um retrocesso sem precedentes; em meio à sinfonia sem nenhuma harmonia que, a pretexto de proteger os semelhantes, abafa a fala do outro, devastando-o, eliminando assim, perigosamente, a partilha das singularidades, encaminhando-nos à pobreza da experiência, como sentenciou Benjamin, sobre o horror da guerra em que não há mais nada para contar além do horror, pois os narradores fazem parte de

uma geração que ainda foi à escola nos carros puxados a cavalos, [e] viu-se de repente num descampado, numa paisagem que nada se manteve inalterada a não ser pelas nuvens, e no meio dela, num campo de forças de correntes e explosões destruidoras, o corpo humano, minúsculo e frágil. ${ }^{30}$

Sobretudo hoje, quando se instala a olhos vistos um golpe político em nosso país, cujas armas são principalmente as palavras inflamadas por um discurso que tem a certeza da verdade e, por isso mesmo, carrega não só a morte das coisas, mas a morte das próprias palavras ao tirar delas o que as tornam preciosas: o acesso à singularidade, o acesso à Coisa; hoje, mais do que nunca, faz-se necessário este contragolpe: o
30. BENJAMIN. $O$ anjo da história, $\mathrm{p}$. 
31. BARTHES. A Preparação do golpe do verso. Hoje, mais do que nunca, é preciso lutar pela literatura, pela poesia, essa "prática da sutileza num mundo bárbaro", porque "a poesia deveria fazer parte dos 'Direitos do Homem'; ela não é 'decadente', ela é subversiva: subversiva e vital”. ${ }^{31}$ É preciso lutar, hoje, mais do que nunca, pela palavra poética, essa potência de nascimento, para que o mundo não morra.

\section{REFERÊNCIAS}

AGAMBEN, Giorgio. Por uma teoria do poder destituinte. Instituto Nicos Poulantzas, 16 nov. 2013. Disponivel em:

<http://5dias.wordpress.com/2014/02/11/por-uma-teoria-dopoder-destituinte-de-giorgio-agamben/>. Acesso em: 30 mar. 2017.

BARTHES, Roland. A preparação do romance, vol. 1. São Paulo: Martins Fontes, 2005

BENJAMIN, Walter. $\mathbf{O}$ anjo da história. Belo Horizonte: Autêntica, 2012

BLANCHOT, Maurice. A parte do fogo. Rio de Janeiro: Rocco, 1997.

CORREIA, Maraíza Labanca. a mais: uma experiência de leitura dos restos em Nuno Ramos. 2016. 212f. Tese (Doutorado em Teoria da Literatura e Literatura Comparada). Faculdade de Letras, Universidade Federal de Minas Gerais, Belo Horizonte, 2016.
DERRIDA, Jacques. Che cos'è la poesia? Coimbra: Angelus Novus, 2003

DERRIDA, Jacques. Essa estranha instituição chamada

literatura: uma entrevista com Jacques Derrida. Belo Horizonte: Ed. UFMG, 2014.

HELDER, Herberto. Le poème continu: somme anthologique. Paris: Instituto Camões; Éditions Chandeigne \& Librairie Portugaise, 2002

HELDER, Herberto. Photomaton \& Vox. Lisboa: Assírio \& Alvim 2006.

HELDER, Herberto. Servidões. Lisboa: Assírio \& Alvim, 2013.

LACAN, Jacques. O seminário, livro 7: a ética da psicanálise. Rio de Janeiro: Jorge Zahar, 2008.

LLANSOL, Maria Gabriela. Carta de Llansol a Eduardo Prado Coelho. 0 fio de água do texto, 31 out. 2011. Disponível em: $<$ https://fiodeaguadotexto.wordpress.com/2011/10/31/carta-dellansol-a-eduardo-prado-coelho/>. Acesso em: 30 mar. 2017.

LLANSOL, Maria Gabriela. Lisboaleipzig 1: o encontro inesperado do diverso. Lisboa: Rolim, 1994.

LLANSOL, Maria Gabriela. Hölder de Hölderlin. Lisboa: Colares editora, 1993

LLANSOL, Maria Gabriela. Onde vais, Drama-Poesia?. Lisboa: Relógio d'Água, 2000 
LOPES, Silvina Rodrigues. A inocência do devir. Lisboa: Vendaval, 2003.

LOPES, Silvina Rodrigues. Anomalia poética. Lisboa: Vendaval 2005.

LOPES, Silvina Rodrigues. Literatura, defesa do atrito. Lisboa: Vendaval, 2003

MALLARMÉ, Stéphane. Divagações. Florianópolis: Ed. da UFSC 2010

\section{MALLARME, Stéphane. Um coup de dés jamais n'abolira le} hasard. Bruges: L'Impremerir, 1914. Disponível em: <https://

math.dartmouth.edu/ doyle/docs/coup/scan/coup.pdf $>$. Acesso em 12 set. de 2017

NANCY, Jean-Luc. Resistência da poesia. Lisboa: Vendaval, 2005

PAULA, Janaina de. Cor'p'oema Llansol. Belo Horizonte: Cas'a'screver, 2016.

RAWET, Samuel. Eu-tu-ele. In: BINES, Rosana Kohl; TONUS, José Leonardo (Org.). Ensaios Reunidos. Rio de Janeiro: Civilização Brasileira, 2008. 